\title{
SOEP
}

SOEPpapers

SOEPpapers
on Multidisciplinary Panel Data Research

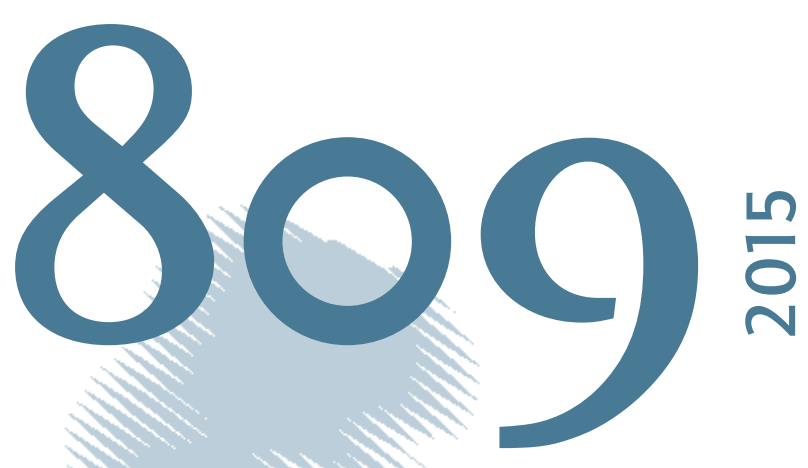

\section{The Political Economy of Risk and Ideology}

Matthew Dimick and Daniel Stegmueller 
This series presents research findings based either directly on data from the German SocioEconomic Panel study (SOEP) or using SOEP data as part of an internationally comparable data set (e.g. CNEF, ECHP, LIS, LWS, CHER/PACO). SOEP is a truly multidisciplinary household panel study covering a wide range of social and behavioral sciences: economics, sociology, psychology, survey methodology, econometrics and applied statistics, educational science, political science, public health, behavioral genetics, demography, geography, and sport science.

The decision to publish a submission in SOEPpapers is made by a board of editors chosen by the DIW Berlin to represent the wide range of disciplines covered by SOEP. There is no external referee process and papers are either accepted or rejected without revision. Papers appear in this series as works in progress and may also appear elsewhere. They often represent preliminary studies and are circulated to encourage discussion. Citation of such a paper should account for its provisional character. A revised version may be requested from the author directly.

Any opinions expressed in this series are those of the author(s) and not those of DIW Berlin. Research disseminated by DIW Berlin may include views on public policy issues, but the institute itself takes no institutional policy positions.

The SOEPpapers are available at

http://www.diw.de/soeppapers

\section{Editors:}

Jan Goebel (Spatial Economics)

Martin Kroh (Political Science, Survey Methodology)

Carsten Schröder (Public Economics)

Jürgen Schupp (Sociology)

Conchita D'Ambrosio (Public Economics)

Denis Gerstorf (Psychology, DIW Research Director)

Elke Holst (Gender Studies, DIW Research Director)

Frauke Kreuter (Survey Methodology, DIW Research Fellow)

Frieder R. Lang (Psychology, DIW Research Fellow)

Jörg-Peter Schräpler (Survey Methodology, DIW Research Fellow)

Thomas Siedler (Empirical Economics)

C. Katharina Spieß (Education and Family Economics)

Gert G. Wagner (Social Sciences)

ISSN: 1864-6689 (online)

German Socio-Economic Panel (SOEP)

DIW Berlin

Mohrenstrasse 58

10117 Berlin, Germany

Contact: Uta Rahmann | soeppapers@diw.de

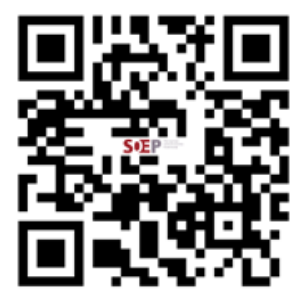




\title{
The Political Economy of Risk ANd IdeOlogy
}

\author{
Matthew Dimick* \\ Daniel Stegmueller ${ }^{\dagger}$
}

\begin{abstract}
This paper argues for the central role of risk aversion in shaping political ideology. We develop a political economy model, which makes explicit the link between risk aversion, the labor market, government policy, and ideology. Our model distinguishes the effects of risk aversion from unemployment risk and our evidence sheds light on debates over explanations for the welfare state. We test our model using a large-scale household panel with an experimentally validated measure of risk aversion. We find that risk aversion is a systematic and important determinant of political-economic attitudes and is at least as important as, if not more so, an individual's position in the income distribution.
\end{abstract}

*SUNY Buffalo Law School, mdimick@buffalo.edu

†University of Mannheim, mail@daniel-stegmueller.com 


\section{INTRODUCTION}

This paper argues for the importance of risk aversion in shaping individuals' political ideology. We argue that risk aversion is linked to political ideology through an economic channel, and formalize this idea in a political-economy model of policy choice. An individual's level of risk aversion shapes how she translates labor market risks, such as income losses due to unemployment, into demand for social protection. Preferences for social protection, in turn, influence an individual's political ideology. To test the predictions from our theoretical model we use survey data on individuals' ideological position combined with an experimentally validated measurement system of risk aversion. This allows us to test the importance of risk aversion with a large representative sample. We develop an explicit measure of risk aversion, which takes into account that survey-based risk aversion measures are imperfect and noisy, and include it in a model of individuals' ideology. Our results show that risk aversion is an important determinant of political attitudes and is at least as important as, if not more so, an individual's position in the income distribution.

Our political-economic argument linking risk aversion and ideology sits alongside a larger literature that posits more and more possible links between basic individual characteristics, such as personality traits, and political ideology and behavior (see, e.g., Mondak and Halperin 2008; Vecchione and Caprara 2009; Gerber et al. 2010; Mondak et al. 2010; Morton, Tyran, and Wengstrom 2011). With respect to this literature, our main contribution is to develop a clear theoretical framework linking basic individual characteristics-in this case, aversion to risk-to political ideology. By no means does our "economic" channel need to be exclusive. In both our theoretical and empirical models we allow for non-economic motivations. But as we show below, our findings concerning the importance of risk aversion is strongly robust even when accounting for important so-called "second dimension" determinants of ideology, such as religiosity.

To the best of our knowledge, we are the first to provide theory and evidence of the ideology effects of risk aversion in the political economy literature. ${ }^{3}$ Risk aversion is central for political economy explanations of economic preferences and ideology, but so far it has not been studied directly. To cite two seminal examples, both Moene and Wallerstein (2001) and Iversen and Soskice (2001) use risk aversion as a fundamental building block in their models. Moene and Wallerstein argue that a decrease in inequality can increase support for redistribution as long

\footnotetext{
${ }^{3}$ For a recent analysis of the effects of risk aversion on political participation outside of the political economy literature, see Kam (2012). Furthermore, we note that whether risk aversion is endogenous to other factors, such as culture (Douglas and Wildavsky 1983; Wildavsky 1987), is a question that remains outside of the scope of this present study, where we focus on individual-level variation in risk aversion.
} 
as individuals are sufficiently risk averse. They assume that individuals are characterized by a degree of risk aversion such that demand for social insurance will increase as income goes up. In Iversen and Soskice (2001), individuals with more specific skills demand more social spending. In particular, their theory predicts that skill specificity, holding income constant, has an effect on social policy preferences if and only if individuals are risk averse. Risk aversion is therefore essential to their asset theory of social policy preferences.

Our argument is different from the one made in the literature linking economic risks to support for social policies. This rapidly growing literature argues that occupational unemployment risk is a critical factor shaping social policy preferences (see for example Cusack, Iversen, and Rehm (2006); Rehm (2009, 2011a); and Rehm, Hacker, and Schlesinger (2012)). We agree that this research program has delivered convincing empirical evidence, demonstrating that unemployment risk is related to the demand for social policy. However, as our political economy model makes clear, an individual's risk aversion is quite distinct from unemployment risk. To see why this is the case, consider a simple example. There are two individuals, neither of whom faces any unemployment risk. Suppose individual $A$ earns $\$ 40,000$ per year, while $B$ earns $\$ 30,000$. All else equal, extensive theory and data would predict that $B$ would prefer more redistribution than $A$, because she is poorer. Now consider individual $C$, who also makes $\$ 40,000$ but is subject to a $25 \%$ chance of becoming unemployed, in which case she earns nothing. The expected income of $C$ is $0.75 \times \$ 40,000=\$ 30,000$. $C$ would also prefer more redistribution than $A$, but in this case, because her expected income is lower. This is the effect that Cusack, Iversen, and Rehm (2006) and Rehm (2009, 2011b) identify.

Let us now introduce the idea of risk aversion. We can capture this idea formally with any concave utility function. To take a simple example, suppose a person values a dollar of income according to the following function: $u(\$)=\sqrt{\$}$. In this case, $B$ values her expected income of $\$ 30,000$ at $\sqrt{30,000}=173.20$. In contrast, $C$ values her identical expected income at $0.75 \times \sqrt{40,000}=150$. Even though both $B$ and $C$ have identical expected income, $B$ 's utility is higher than $C$ 's. Notice that if $C$ were making a bet, she would take the $\$ 30,000$ with certainty, and forgo the three-quarters chance of getting $\$ 40,000$ even though the expected value of the two bets is equal.

Indeed, C's refusal to accept a "fair bet," can help us understand the demand for social insurance. Suppose that $C$ is employed and pays an insurance company $\$ 4,000$ - or that the government taxes $C$ 's income at a $10 \%$ rate-in exchange for the right to receive $\$ 4,000$ if she becomes unemployed. This makes her expected utility $0.75 \times \sqrt{36,000}+0.25 \times \sqrt{4,000}=$ 158.11. Having insurance improves $C$ 's utility over that without any insurance. But note that her expected income with insurance is now lower: $0.75 \times \$ 36,000+0.25 \times \$ 4,000=$ 
$\$ 28,000<\$ 30,000$. This underscores the importance of the concavity of the utility function: an individual values a dollar less when employed than when unemployed. She would therefore prefer to pay to have more income when unemployed. ${ }^{4}$

These examples illustrate the distinct behavioral assumptions that differentiate the effects of unemployment risk from risk aversion on social policy preferences. This distinction is important because it is linked with very different explanations for the development of the welfare state. One perspective views the welfare state as a mechanism to redistribute income from rich to poor. Another views the welfare state as a vehicle for providing insurance to protect against social and economic risks. Unemployment risk is therefore a redistributive motive: it increases the demand for social policy because it reduces expected income. In contrast, risk aversion is inherently an insurance motive: it increases demand for social policy because it mitigates the noisiness of the expected stream of income. Moreover, without risk aversion, the reason that $B$ and $C$ in the examples above prefer more social spending is behaviorally equivalent: they are both poorer than $A$. In contrast, with risk aversion, $C$ prefers more social spending than $B$, even though they have identical expected income.

In the next section we develop a formal model of the labor market, government policy, and political ideology. From this model, we then derive testable implications for how risk aversion, income, and unemployment risk influence individuals' social policy preferences.

\section{MODEL}

Consider a continuum of individuals of size one, distinguished by two characteristics: their productivity (or wage rate if the labor market is perfectly competitive), $w$, and their degree of risk aversion, $\sigma$. We assume that $w \in W=\mathbf{R}_{+}$and $\sigma \in \Sigma=\mathbf{R}_{+}$respectively have cumulative distribution $G(w)$ and $H(\sigma)$, positive probability density $g(w)$ and $h(\sigma)$, have finite expectation, and are i.i.d. Further, let $s \in S=W \times \Sigma$. A type-s worker thus has characteristics $(w, \sigma)$.

Each individual has a utility function over a set of policies, $i \in N, N=\{1,2, \ldots, n\}$. We define an individuals' ideal points over policies as her ideology. ${ }^{5}$ In this conception, ideology is explicitly multidimensional. However, in many cases, individuals must make

\footnotetext{
${ }^{4}$ More generally, as shown in Rothschild and Stiglitz (1970), we can say that if a gamble $Y$ is a mean-preserving spread of a gamble $X$ or, equivalently, if $X$ second-order stochastically dominates $Y$, then a person with any concave utility function will prefer $X$ to $Y$.

${ }^{5}$ Our definition of ideology collapses the distinction between that term and an individual's policy preferences. Without altering results, we could retain this nuance by using a model proposed by Hinich and Munger (1992) or Hinich and Munger (1996).
} 
single-dimensional choices, such as choosing between a left versus a right politician in an election or, as in our dependent variable, a self-placement on a left-right ideological scale. Therefore, the utility, $V_{s}$, of an individual with characteristics $s$ over the $n$-dimensional policy space takes the form:

$$
V_{s}\left(x_{1}, x_{2}, \ldots, x_{n}\right)=\sum_{i=1}^{n}-\left(x_{i}-\bar{x}_{i, s}\right)^{2}
$$

where $x_{i}$ is the value for policy $i$ and $\bar{x}_{i, s}$ is individual $s$ 's ideal point for that policy. We highlight two features. First, we say that an individual is further left, on a left-right ideological scale, if $s$ 's ideal point for policy $i, \bar{x}_{i, s}$, is larger than the value for some other individual, $t$, $\bar{x}_{i, s}>\bar{x}_{i, t}$. (Also note that the value for policy $i$ that maximizes each individual's utility is the one that equals her ideal point.) Although this function assumes that the effect of one policy choice on utility is independent of the other policy choices, this is a stronger assumption than necessary. All we require is that a shift of policy preferences on a single dimension have straightforward and discernible effects on an individual's overall ideological position.

An individual's ideal point for social spending is an endogenous variable in our model. We posit that it is systematically related to a person's economic situation. To capture this, we assume that each individual also has a von Neumann-Morgenstern utility function $u(c)$ over final consumption. The function $u$ is twice continuously differentiable, strictly increasing, and concave. We employ a standard functional form for analyzing risk aversion, termed constant relative risk aversion:

$$
u(c)=\frac{c^{1-\sigma}}{1-\sigma}
$$

The label for this functional form comes from the fact that the coefficient of risk aversion is constant relative to consumption: $\sigma=-c u^{\prime \prime}(c) / u^{\prime}(c)$. Thus, this form straightforwardly parametrizes the level of risk aversion, with a larger $\sigma$ signifying a greater aversion to risk.

Workers can be employed or unemployed. A worker with characteristics $s$ is employed with probability $q_{s} \equiv q(w, \sigma) \in[0,1]$ and unemployed with probability $1-q_{s} \cdot{ }^{6}$ When employed, their consumption is denoted $c_{E}$ and $c_{N}$ when unemployed. They can also receive transfers from the government, denoted $b$, that also may depend on their employment status. Fiscal policy is characterized by two parameters: first, the government raises revenue by taxing income, $y$, at a flat-rate, $\tau \in[0,1]$. Second, following Moene and Wallerstein (2001), $\chi \in[0,1]$ determines the share of revenue spent on transfers to employed workers. The parameter $\chi$

\footnotetext{
${ }^{6}$ The (un)employment rate varies with a worker's type, but is otherwise exogenous in our model. In separate work we endogenize unemployment in a formal model. We could also produce a dynamic model with exogenous entry and exit rates into and out of employment, as in Moene and Wallerstein (2001), but doing so would add notational complexity without adding any additional insight to our current model.
} 
clarifies the importance of policy design in shaping social spending preferences, especially when individuals are risk averse and desire insurance. In particular, when transfers are targeted only to employed workers $(\chi=1)$, fiscal policy to an important extent is purely redistributive. ${ }^{7}$ On the other hand, when transfers are targeted specifically to the unemployed $(\chi=0)$, government transfers come in the form of social insurance. The government is subject to a balanced budget constraint:

$$
b=\tau \bar{z},
$$

where $\bar{z}$ represents the mean income of income-earning (i.e., employed) workers:

$$
\bar{z}=\int_{\sigma} \int_{w} q(w, \sigma) y(w) d G(w) d H(\sigma) .
$$

Letting $b_{E}$ be the size of the transfer going to employed workers, $\bar{q} \equiv \int_{\sigma} \int_{w} q_{s} d G(w) d H(\sigma)$ the average employment rate, $b_{N}$ the size of the transfer going to unemployed workers, and $1-\bar{q}$ the average unemployment rate, we can decompose the government's budget constraint (3) into its separate components:

$$
\bar{q} b_{E}+(1-\bar{q}) b_{N}=\chi \tau \bar{z}+(1-\chi) \tau \bar{z}
$$

Since by definition $\bar{q} b_{E}=\chi \tau \bar{z}$ and $(1-\bar{q}) b_{N}=(1-\chi) \tau \bar{z}$ we can solve for the transfer to each group:

$$
b_{E}=\frac{\chi \tau \bar{z}}{\bar{q}} \quad \text { and } \quad b_{N}=\frac{(1-\chi) \tau \bar{z}}{1-\bar{q}}
$$

Thus, all revenue goes to employed workers when $\chi=1$, but goes to all unemployed workers when $\chi=0$. In contrast to these two scenarios, transfers are universal when $\chi=\bar{q}$.

When employed, workers earn income, $y$, by supplying labor, $l \in[0, \infty)$. Specifically, $y=w l$. However, supplying labor is also costly. The cost of supplying labor is $C(l)$, with the cost of labor measured in units of the consumption good and where $C(\cdot)$ is a differentiable, increasing, and strictly convex function, with $C(0)=0$ and $\lim _{l \rightarrow \infty} C^{\prime}(l)=\infty$. Thus, the consumption of an employed worker is:

$$
c_{E}=(1-\tau) w l+b_{E}-C(l)
$$

\footnotetext{
${ }^{7}$ Not to an unconditional extent, insofar as unemployment is an important determinant of economic inequality.
} 
while the consumption of an unemployed worker is:

$$
c_{N}=b_{N}
$$

Putting all the pieces together, we assume that individuals' expected consumption utility takes the form of:

$$
U(w, \sigma) \equiv q_{s} u\left(c_{E}\right)+\left(1-q_{s}\right) u\left(c_{N}\right) .
$$

To summarize the model and its key elements, the timing of events takes place in the following order,

1. Let $\mathbf{x}_{1}$ and $\mathbf{x}_{2}$ represent two policy vectors (e.g., the policy platforms of two different candidates). Individuals choose $V_{s}^{*}=\max \left[V_{s}\left(\mathbf{x}_{1}\right), V_{s}\left(\mathbf{x}_{2}\right)\right]$ given their ideal points, $\left(\bar{x}_{1, s}, \ldots, \bar{x}_{n, s}\right)$. A larger ideal point represents a more leftist political position on that policy issue.

2. An individual's social spending ideal point, $\bar{x}_{i, s}=\tau_{s}^{*}$, is determined by choosing a tax rate, $\tau$, to maximize her expected consumption utility, $U(w, \sigma)$, subject to a balanced-budget constraint, which allocates the revenue to employed workers, $b_{E}$, and unemployed workers, $b_{N}$, according to the share $\chi$.

3. When employed, workers choose how much labor to supply, $l$, to maximize their utility $u\left(c_{E}\right)$.

\section{A. Equilibrium}

An equilibrium of the model is characterized by workers' optimal choices of labor supply, $l_{s}$, tax rate, $\tau_{s}$, and their social policy preferences, $\bar{x}_{i, s}$. For each individual, it is straightforward to show that these choices exist and are unique. We do this in Proposition 2 in the Appendix, but offer the intuition here. By backward induction, we start with workers' choice of labor supply. Labor supply is increasing in workers' productivity, so more productive workers supply more labor and earn higher incomes. Also, labor supply is decreasing in the tax rate. This fact creates a disincentive effect which ensures that no individual chooses a tax rate larger than one. This choice of the tax rate captures workers' social spending preferences.

Identifying workers' social spending ideal points helps locate individuals in a left-right ideological space. Since social spending constitutes one dimension of a person's ideology, ideology and social spending preferences are linked. Say policy $i$ represents social spending, then $\bar{x}_{i, s}\left(\tau_{s}^{*}\right)=\tau_{s}^{*}$. Using the ideology equation in (1), we then can say that anything that 
increases (decreases) social spending preferences of individual $s$ moves her ideologically to the left (right): $\partial \bar{x}_{i, s} / \partial \tau_{s}^{*}=1>0$.

\section{B. Comparative Statics}

We now turn to the comparative statics of the model. Specifically, this section analyzes implications of risk aversion, income, and unemployment for political ideology.

Proposition 1. (Political ideology). The effect of risk aversion $(\sigma)$, income $(y)$, and unemployment rate $(1-q)$ on individuals' left-right ideological location $\left(\bar{x}_{i, s}=\bar{x}\right)$ are as follows:

1. (Risk aversion). Holding income and unemployment risk constant, a greater degree of risk aversion (larger $\sigma$ ) makes a person more left-leaning (larger $\bar{x}$ ) for all $\chi<1$.

2. (Income). Holding risk aversion and unemployment risk constant,

a) (Transfers targeted to unemployed, $\chi=0$ ). There exists a value of $\sigma=\sigma^{\prime}$ such that if $\sigma<\sigma^{\prime}$, then an increase in income (larger $y$ ) makes an individual less leftleaning (smaller $\bar{x}$ ). If $\sigma \geq \sigma^{\prime}$, then an increase in income makes an individual more left-leaning (larger $\bar{x}$ ).

b) (Universal transfers, $\chi=\bar{q}$ ). There exists a value of $\sigma=\sigma^{\prime \prime}>\sigma^{\prime}$ such that if $\sigma<\sigma^{\prime \prime}$, then an increase in income (larger y) makes an individual less left-leaning (smaller $\bar{x}$ ). If $\sigma \geq \sigma^{\prime \prime}$, then an increase in income makes an individual more left-leaning (larger $\bar{x}$ ).

c) (Transfers targeted to employed, $\chi=1$ ). For any level of risk aversion, $\sigma$, an increase in income (larger y) makes an individual less left-leaning (smaller $\bar{x}$ ).

3. (Unemployment). Holding risk aversion and income constant, an increase in an individual's unemployment rate (larger $1-q$ ) makes her more left-leaning (larger $\bar{x}$ ) for all $\chi<1$.

Proof. See Appendix A.2

This proposition establishes the testable predictions of the model. Part 1 is the core message of our paper. It says that the more risk averse a person is, holding both income and unemployment risk constant, the more left-leaning she becomes. The reason for this follows from the concavity of a person's utility function. More risk aversion means a more concave utility function, which implies that a person puts less value on having an additional 
dollar if employed, and more value on an additional dollar if unemployed. Therefore, a more risk averse person prefers more social insurance than a less risk averse person. This greater demand for social insurance is aligned with a more left, rather than right, ideological position.

Part 2 is our model's predictions about the conditional relationship between income and political ideology. We argue that the strength of the relationship between income and social spending preferences depends on an individual's level of risk aversion. In either the targetedto-unemployed or universal case, an increase in income may increase a person's preferences for social spending if her aversion to risk is large enough. Intuitively, a highly risk-averse person wants more insurance to protect against the chance of a larger fall in income. The difference between the two scenarios is that targeted transfers are "pure" insurance, while universal transfers have an inherently redistributive element to them. Thus, in the universal case, the degree of risk aversion required to make increasing income have a positive effect on social spending preferences is larger. In contrast, when transfers are targeted to the employed, transfers have no insurance element and social spending preferences are strictly decreasing in income. Our result has clear implications for existing models of redistribution. For example, Moene and Wallerstein (2001) assume that all individuals are sufficiently risk averse so that preferences for social insurance will be increasing in income. This assumption is critical for their (macro-level) political economy argument that a reduction in inequality can lead to an increase in redistribution.

Finally, Part 3 serves primarily to distinguish our focus on risk aversion from an analysis based on occupational unemployment risk. Our model predicts that an increase in unemployment risk makes a person more left-leaning through her social spending preferences. Regardless of how transfers are targeted, the fundamental mechanism is the same: higher risk of unemployment reduces expected income. A higher risk of unemployment makes expected income closer to the individual's unemployed income, which is lower than her income when employed. Thus, when the expectation of unemployment increases, it is not risk aversion, but expectations of lower income that induce an increased demand for social spending.

In our empirical analysis, developed below, we will first focus on the role of risk aversion (testing Part 1 of our proposition). In these models we will include only the unconditional effect of income, which makes it easier to compare our results to previous research. In the next step we focus on the interaction between income and risk aversion (testing Part 2). Before doing so we translate our theoretical results into a testable model. 


\section{Testing THe Model}

Using the first-order condition of an individual's utility in equation (7), we implicitly obtain a function for a person's location in ideological space, $\bar{x}_{s}(\sigma, y)$, via her ideal social spending policy preferences $\left(\tau^{*}\right)$, as a function of her level of risk aversion, $\sigma$, and her income, $y$. The first-order Taylor expansion of $\bar{x}_{s}(\sigma, y)$ is:

$$
\bar{x}_{s}=\alpha+\frac{\partial \bar{x}_{s}}{\partial \sigma} \sigma+\frac{\partial \bar{x}_{s}}{\partial y} y+\sum \frac{\partial \bar{x}_{s}}{\partial r} r
$$

where $\sum r$ is a list of some additional ideology-influencing factors (based on previous research) that we control for. Thus, our regression equation takes the form:

$$
z_{i}=\gamma \psi_{i}+\delta y_{i}+\sum \beta_{i} r_{i}
$$

where $z_{i}$ is an individual's ideological position. Our empirical individual-level measure of risk aversion is denoted by $\psi_{i}$, and its coefficient corresponds with our central theoretically-derived hypotheses of Proposition 1: $\gamma=\partial \bar{x}_{s} / \partial \sigma, \delta=\partial \bar{x}_{s} / \partial y$. Hence, if $\gamma$ is larger than zero, both statistically and substantively, we obtain support for the expectation that $\partial \bar{x}_{s} / \partial \sigma>0$ from Part 1 of Proposition 1. Likewise, if $\delta$ is less than zero, our expectation is confirmed that $\partial \bar{x}_{s} / \partial y<0$ from Part 2 .

Our dependent variable is an individual's ideology, i.e., his or her position on a left-right dimension. We assume that more left positions imply a stronger preference for welfare spending and redistribution. Our argument has general implications for welfare and spending preferences. Thus, we opt for using a broad explanandum instead of the more commonly used more specific question on redistribution preferences (which focuses narrowly on the rich-poor income gap). Indeed, a question about redistribution and inequality may not capture a risk view of social policy preferences, which has a fundamentally different behavioral foundation, as we have argued. ${ }^{8}$

\section{DATA}

We use data from the German Socio-Economic Panel (SOEP 2013), an ongoing longitudinal survey of German households. It is carefully constructed to be representative of the German

\footnotetext{
${ }^{8}$ Our ideal question would be one about social spending, since it would be broad enough to capture both redistributive and insurance motives. In the absence of that, we believe our ideology measure to be the next best alternative.
} 
adult population. Information on households and every adult individual living in that household is obtained through face-to-face interviews held annually (mainly between January and May). SOEP provides high-quality data on individuals' labor market activities, such as income, work experience, and unemployment spells. ${ }^{9}$

What makes this study ideal for our purpose, is that in 2009 it includes a detailed measurement instrument of risk aversion. It consists of a set of items assessing the extent to which individuals engage in risky behaviors in different contexts. Using risk measures as part of a large-scale panel study allows us to study the effect of risk aversion in a proper random sample allowing inference to the total population. ${ }^{10}$ However, compared to a laboratory experiment, our measure of risk aversion might be both less reliable and less valid. The latter concern is alleviated by an explicit validation study, which tested the survey measures using a field experiment. The former is explicitly addressed in our model. We construct a covariate measurement error model (Wansbeek and Meijer 2000), which takes into account the limited reliability of survey-based measures of risk aversion.

We select our sample as follows. Starting from the full sample in 2009, we use all SOEP samples (A to $\mathrm{H}$ ) except an oversample of high-income earners (sample $\mathrm{G}$ ). This yields a sample of 18,996 individuals. We focus on working-age individuals and exclude those still in full-time education. This provides us with a sample of 13,948 individuals. After deleting cases with missing covariates, we obtain a final sample size of 13,464 respondents.

Risk aversion measures and experimental validation. In order to test our model we require a measure of risk aversion that fully captures individual differences. We construct our measure using a set of risk items included in SOEP wave 2009 where individuals are asked to what extent they take risks in various contexts of daily life (Weber, Blais, and Betz 2002). These include taking risks while driving, in leisure time, doing sports, in financial matters, as well as an individual's general willingness to take risk. All responses are given on an 11-point scale, where 0 represents "unwilling to take risks", while 11 represents "fully prepared to take risks". ${ }^{11}$ In our empirical application below we reverse this scale, such that higher values indicate more aversion to taking risks.

\footnotetext{
${ }^{9}$ For more information on the SOEP contents and structure see Haisken-DeNew and Frick (2005) and Wagner, Frick, and Schupp (2007).

${ }^{10}$ Furthermore, an advantage of using a survey measurement instrument is that it allows us to derive individual risk preferences without having to recover behavioral parameters using (arbitrary) identifying assumptions. The downside of our survey-based measures of risk is that they are not incentive compatible, a problem that is overcome by laboratory experiments where real money is at stake (for a discussion see e.g., Camerer and Hogarth 1999; Holt and Laury 2002). We address this concern by using a behaviorally validated survey instrument combined with an explicit measurement model.

${ }^{11}$ The exact question wording is "How would you assess your preparedness to take risks in the following areas...?"
} 
In order to test the behavioral validity of these survey questions, Dohmen et al. (2005) carry out a large scale field experiment based on a representative sample of 450 individuals. ${ }^{12}$ Participants of the experiment completed parts of the SOEP questionnaire (including our general risk item), and then took part in a lottery experiment (cf. Holt and Laury 2002). Results show that survey items used to measure general risk predict actual risky choices rather well (Dohmen et al. 2005). Thus, they are "uniquely valid instruments" (Dohmen et al. 2005: 18) capturing individual heterogeneity in risk preferences (and actual risk-taking).

Ideology. Our dependent variable is the standard measure of ideology, similar to the one used in the American National Election Studies. It asks individuals to place themselves on an 11-point scale with labeled endpoints, ranging from "far left" (0) to "far right" (10). ${ }^{13}$ We reverse this scale so that higher values represent left positions. ${ }^{14}$

Individual characteristics. We do not include a huge number of "control variables" in our models, to avoid Achen's (2005) garbage can regression problem arising from too many (endogenous) covariates. However, we include basic individual characteristics, to capture heterogeneity between individuals. Age is measured in years, gender via an indicator variable for being female. Education is captured by years of schooling. We also include an indicator variable for growing up in the former GDR to capture possibly lasting effects of communism (Alesina and Fuchs-Schündeln 2007). Finally, a respondent's income is measured by his or her gross income from labor in the previous calendar year. In more extended specifications, we include further individual and household characteristics. These include indicator variables for being unemployed, self-employment, a union member, and/or of non-German nationality. We also include the number of hours worked, the duration of one's experience of unemployment in the previous calendar year (in months), as well as a variable capturing household size. ${ }^{15}$ Descriptive statistics of all variables are available in appendix A.3.

\footnotetext{
${ }^{12}$ The field experimental sample was obtained using the random walk method, using face-to-face interviews with CAPI between June and July 2005.

${ }^{13}$ The actual question text is: "In politics, people often talk about "left" and "right" when describing different political views. When you think about your own political view, how would you rate them on the scale below?".

${ }^{14}$ We validate that the left-right variable used here does have significant economic content. We use 2,519 cases from the German portion of the European Social Survey, which includes both a left-right measure similar to the one used in this paper as well as a measure of redistribution preferences widely used in politico-economic research. Using a scaled ordered logit model (Anderson 1984) we relate redistribution preferences to the left-right scale. The relationship between left-right position and redistribution preferences is highly significant. The estimated effect of left-right position on redistribution preferences is 0.485 with a standard error of 0.084 .

${ }^{15}$ Union membership was not assessed in the panel wave used in our analysis. Therefore, we matched this information from an earlier interview (two waves prior).
} 


\section{STATistical Specification}

Our statistical model consists of a simple linear model relating ideology to risk aversion. However, our proxy measures of risk aversion are imperfect and simply including them on the right-hand side of our model introduces a clear errors-in-variables problem (Chesher 1991). We solve this by adjoining a measurement system (Fuller 1987: ch.4) to our linear model. This allows us to generate reliable measure of risk aversion and to properly include the uncertainty arising from our imperfect proxies (cf. Skrondal and Rabe-Hesketh 2004).

\section{A. Measuring risk aversion}

For each respondent $i(i=1, \ldots, N)$ we have several measures of risk aversion $x_{i 1} \ldots x_{i J}$. Based on our theoretical model (and in line with its usual conceptualization in economics) we argue that each individual can be assigned a scalar value of risk aversion, denoted $\psi_{i}$. Thus, observed risk aversion measures $x_{i j}$ are results of unobserved, or latent, levels of $\psi_{i}$. By modeling how this latent variable generates observed risk measures we can generate estimates of $\psi_{i}$, which is what we are ultimately interested in (Jackman 2009: ch.9).

We stack available risk measures for each individual into a length- $J$ vector $x_{i}=\left(x_{i 1}, \ldots, x_{i J}\right)^{\prime}$ and model $\boldsymbol{x}_{i}$ as a function of $\psi_{i}$ via the following linear system:

$$
\boldsymbol{x}_{i}=\boldsymbol{\mu}+\lambda \psi_{i}+\boldsymbol{\epsilon}_{i}
$$

Here $\mu$ is a vector of means (or intercepts), while $\lambda$ is a length $J$ vector of coefficients relating changes in $\psi_{i}$ to changes in $\boldsymbol{x}_{i}$. Finally, $\boldsymbol{\epsilon}_{i}$ is a vector of regression residuals. ${ }^{16}$ The measurement system is completed by assigning a distribution to the latent variable or random coefficient, $\psi=\left(\psi_{1}, \ldots, \psi_{N}\right)^{\prime}$. Following established convention we use a normal distribution centered at zero: $\psi \sim N(0, \omega){ }^{17}$

To identify the model both scale and orientation of $\boldsymbol{\psi}$ need to be set (Anderson and Rubin 1956; Wansbeek and Meijer 2000: 208). This can be achieved by fixing the variance, $\omega$, and putting inequality constraints on one of the elements of $\lambda$, which is the strategy used in most ideal-point models (e.g., Quinn 2004). Alternatively, if we put a scalar restriction on one of the elements of $\lambda$, we identify both the orientation and the scale of our latent risk measure

\footnotetext{
${ }^{16}$ We assume that $\operatorname{Cov}\left(\epsilon_{i j}, \epsilon_{i k}\right) \forall j, k$, i.e., the standard assumption that, conditional on the latent variable, measurements are independent (Jackman 2008).

${ }^{17}$ See Skrondal and Rabe-Hesketh (2004) for a general discussion of random coefficient/factor models.
} 
(which is then on the same scale as our measures). ${ }^{18}$ We follow the latter strategy and fix $\lambda_{1}=1$. Thus, a higher value of $\psi_{i}$ implies that an individual is less prepared to take risks in several areas of life, in other words, she is more risk averse.

Before proceeding to our model for ideology, we address an objection to our measurement strategy. A critical reader might argue that assuming a normal distribution for latent risk aversion is an arbitrary choice. While there is research arguing for this choice on the grounds of its robustness against misspecification (Bartholomew 1988; Wedel and Kamakura 2001), note that this assumption is not necessary for our model. Jettisoning the normal distribution assumption, we also estimate $f(\psi)$ semi-parametrically by approximating it using a finite mixture of normals (Ferguson 1983):

$$
f(\psi)=\sum_{k=1}^{K} \pi_{k} \phi\left(\psi \mid \mu_{k}, \sigma^{2}\right)
$$

Here $\phi(\cdot)$ is the normal density, and $\pi=\left(\pi_{1}, \ldots, \pi_{K}\right)^{\prime}$ is discrete with mass at $\left(\mu_{k}, \sigma^{2}\right)$. To insure identification $\sum_{k} \pi_{k}=1$. Even with very few mass points ( $K$ being as little as two) finite normal mixtures are flexible enough to approximate a wide number of densities. See Rossi (2014: ch.1) and Skrondal and Rabe-Hesketh (2004: ch.6) for an extended discussion. In our empirical application we set $K=3$ to produce a non-parametric estimate of $f(\psi)$ in addition to the one based on the normal distribution described above. With these $\psi_{i}$ estimates in hand we can proceed to estimate the relationship between risk aversion and ideology.

\section{B. Ideology}

For each individual $i$ we have a scalar measure of ideology, $y_{i}$, her income, $w_{i}$, and a vector of social characteristics, $\boldsymbol{z}_{i}$. We model the relationship between risk aversion, $\psi_{i}$, and ideology using the following specification:

$$
y_{i}=\boldsymbol{z}_{i}^{\prime} \boldsymbol{\beta}+\gamma \psi_{i}+\delta w_{i}+v_{i}
$$

Here $\gamma$ is the regression coefficient associated with the risk aversion effect, $\partial \bar{x}_{s} / \partial \sigma$, and $\delta$ corresponds to the income effect $\partial \bar{x}_{s} / \partial w$. Systematic differences in social characteristics of individuals are captured by coefficient vector $\boldsymbol{\beta}$. Finally, $v_{i}$ are white noise residuals.

\footnotetext{
${ }^{18}$ To be more precise, we can identify the model from covariances alone. We have $J(J-1) / 2=10$ covariances, from which we want to identify: 5 elements in $\lambda, 5$ elements in $\epsilon$ and $\omega$. Clearly, the model is not identified without restrictions. Fixing one element of $\boldsymbol{\lambda}$ identifies the model.
} 


\section{Estimation}

We implement the model in a fully Bayesian framework (Gill 2014; Jackman 2009), which allows for straightforward estimation of all $\psi_{i}$ and fully takes into account the uncertainty arising from our measurement of risk aversion. We estimate our system of measurement equations in (10) jointly with equation (11). Our Bayesian specification is completed by assigning prior distributions to all free model parameters. We choose vague or "uniformative" prior values for all model parameters so that our results do not depend on prior information (see appendix A.4 for details). The joint model can be estimated via Gibbs sampling. We ran two chains for 40,000 iterations discarding the first 10,000 as transient phase of the Gibbs sampler. ${ }^{19}$ All results reported below are based on the remaining 30,000 posterior samples.

\section{RESUlTs}

\section{A. Risk aversion}

We start by discussing results from our measurement of risk aversion. Table 1 shows parameter estimates (posterior means) together with an interval measure of uncertainty $90 \%$ highest posterior density regions - in brackets. ${ }^{20}$ The first two columns, labeled $\psi^{(P)}$ show estimates based on our parametric model with an assumed normal distribution on latent risk aversion, while the last remaining two columns, labeled $\psi^{(N P)}$, display non-parametric estimates.

We find strong evidence that latent levels of risk aversion drive observed (or, more precisely, reported) levels of risk aversion. Estimates in columns $\lambda_{j}$, which show the strength of the relationship between $\psi_{i}$ and risk measures $x_{i j}$, are substantial. For example, a unit increase in latent risk aversion induces a decrease in willingness to take risk in financial matters by $0.74 \pm$ 0.01 points. The relationship between $\psi$ and other measures is of similar magnitude, with small confidence intervals, indicating that their relationship is highly statistically significant. Estimates from our non-parametric model are slightly smaller, but still highly significant (both in the substantive and statistical sense).

The distribution of estimated risk aversion for all individuals is displayed in Figure 1. We calculate posterior means for each $\psi_{i}$ and estimate their distribution via Gaussian kernel

\footnotetext{
${ }^{19}$ Standard diagnostics did not indicate any convergence issues and Monte Carlo standard errors (i.e., simulation noise) was an order of magnitude smaller than our estimates.

${ }^{20} \mathrm{~A}$ region $R$ is a $100(1-\alpha)$ percent HPD region for parameter $\theta$ if (1) $P(\theta \in R)=1-\alpha$ and (2) $P\left(\theta_{1}\right) \geq P\left(\theta_{2}\right)$ for all $\theta_{1} \in R$ and $\theta_{2} \notin R$, i.e., it yields an interval estimate with the added requirement that each value in the interval is larger than those outside of it (Gill 2014: 46).
} 
Table 1: Parameter estimates I: risk aversion measurement system. Willingness to take risks as function of latent risk aversion. Parametric $\left[\psi^{(P)}\right]$ and nonparametric $\left[\psi^{(N P)}\right]$ distribution estimates.

\begin{tabular}{lccccc}
\hline & \multicolumn{2}{c}{$\psi^{(P)}$} & & \multicolumn{2}{c}{$\psi^{(N P)}$} \\
\cline { 2 - 3 } \cline { 5 - 6 } Risk behavior & $\mu_{j}$ & $\lambda_{j}$ & & $\mu_{j}$ & $\lambda_{j}$ \\
\hline Driving & 6.798 & 1.000 & & 3.939 & 1.000 \\
& {$[6.762,6.836]$} & {$[1.000,1.000]$} & & {$[3.834,4.053]$} & {$[1.000,1.000]$} \\
Financial & 8.023 & 0.738 & & 5.923 & 0.734 \\
& {$[7.993,8.052]$} & {$[0.717,0.757]$} & & {$[5.830,6.012]$} & {$[0.716,0.755]$} \\
Leisure, Sports & 6.606 & 1.079 & & 3.481 & 1.093 \\
Occupation & {$[6.569,6.641]$} & {$[1.053,1.104]$} & & {$[3.363,3.601]$} & {$[1.067,1.117]$} \\
& 6.563 & 1.045 & & 3.564 & 1.050 \\
General & {$[6.526,6.602]$} & {$[1.018,1.070]$} & & {$[3.447,3.678]$} & {$[1.024,1.075]$} \\
& 6.124 & 0.862 & & 3.718 & 0.842 \\
& {$[6.093,6.154]$} & {$[0.842,0.883]$} & & {$[3.623,3.812]$} & {$[0.822,0.862]$} \\
\hline
\end{tabular}

Notes: Based on 30,000 MCMC samples. Nonparametric estimate of $f(\psi)$ based on $\mathrm{K}=3$.

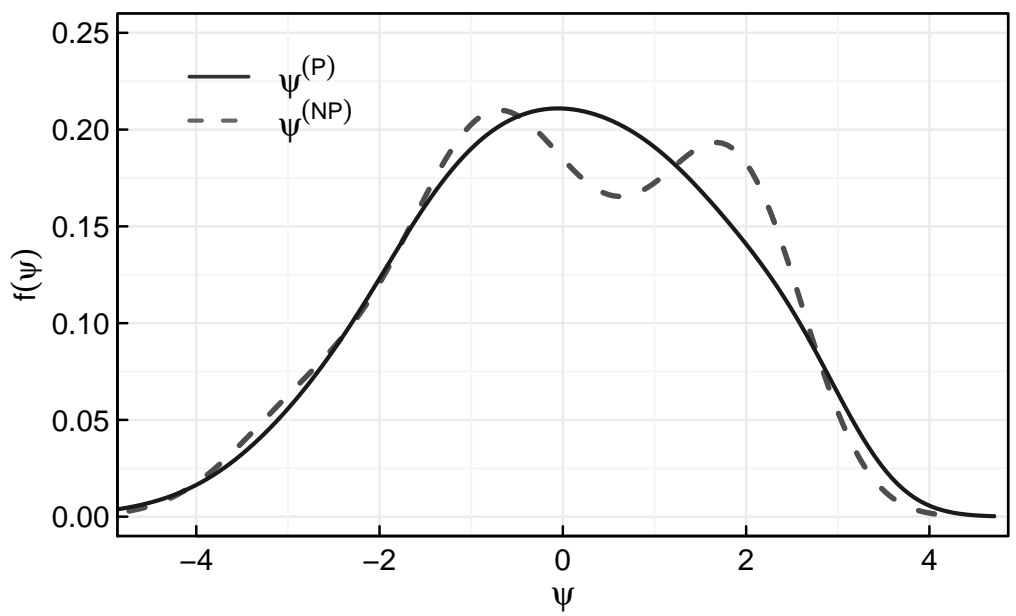

Figure 1: Distribution of latent risk aversion $\psi$. Parametric and non-parametric estimates. Kernel density plots (Gaussian kernel with bandwidth 0.6 evaluated on 200-point grid).

density estimation on a 200-point grid. Figure 1 reveals substantial heterogeneity in levels of risk aversion between individuals. Even our parametric model yields a posterior distribution of risk aversion with quite heavy tails. This phenomenon is even more marked when using our non-parametric estimates. They show some evidence of bi-modality, with a substantive part of the population being rather averse to taking risks. 
Table 2: Parameter estimates II: ideology equation. Political ideology as function of risk aversion, income, and individual background characteristics.

\begin{tabular}{|c|c|c|c|c|}
\hline & (1) & (2) & (3) & (4) \\
\hline Income & $\begin{array}{c}-0.043 \\
{[-0.056,-0.031]}\end{array}$ & $\begin{array}{c}-0.039 \\
{[-0.052,-0.026]}\end{array}$ & $\begin{array}{c}-0.039 \\
{[-0.052,-0.026]}\end{array}$ & $\begin{array}{c}-0.029 \\
{[-0.047,-0.010]}\end{array}$ \\
\hline$\psi^{(P)}$ & & $\begin{array}{c}0.051 \\
{[0.036,0.067]}\end{array}$ & & $\begin{array}{c}0.050 \\
{[0.032,0.066]}\end{array}$ \\
\hline$\psi^{(N P)}$ & & & $\begin{array}{c}0.055 \\
{[0.039,0.070]}\end{array}$ & \\
\hline \multicolumn{5}{|l|}{ Controls } \\
\hline Basic $^{\mathrm{a}}$ & yes & yes & yes & yes \\
\hline Extended $^{\mathrm{b}}$ & no & no & no & yes \\
\hline $\mathrm{N}$ & 13464 & 13464 & 13464 & 11065 \\
\hline Deviance & 307336 & 307282 & 307264 & 251520 \\
\hline
\end{tabular}

Notes: Based on 30,000 MCMC samples. ${ }^{\mathrm{a}}$ Basic covariate set includes age, gender, years of education, and an indicator variable for growing up in East Germany. ${ }^{\mathrm{b}}$ Extended covariate set includes indicators for unemployment and selfemployment, union membership, non-German nationality, and household size.

\section{B. Ideology}

Estimates The role risk aversion plays in shaping ideology is demonstrated in Table 2. It shows parameter estimates for equation (11) together with their 90\% HPD regions for a range of model specifications. ${ }^{21}$ Our baseline model (1) simply includes a respondent's income as distance from the country mean. In line with recent political economy research on microlevel preferences, higher income distance is associated with a more conservative political outlook (and once more underscores the strong economic content of our dependent variable). Model (2) proceeds to a test of our argument, by including our (parametric) estimates of individuals' risk aversion. Holding income distance constant, we find a positive effect of risk aversion, indicating that more risk averse individuals are more left-leaning. We will explore the substantive magnitude of this below; for now we note that the relationship clearly is statistically different from zero, as indicated by the HPD region bound away from zero. When using a non-parametric estimate of risk aversion in model (3) we reach a strikingly similar conclusion, indicating that our core result does not depend on the assumption of normally distributed latent risk aversion.

\footnotetext{
${ }^{21}$ Note that we split the presentation of estimates into two tables for reasons of exposition. The model was estimated jointly carrying through all uncertainty from the risk aversion estimation stage.
} 
Table 3: Bayesian tests of central hypotheses

\begin{tabular}{lrr}
\hline Hypothesis $\left(H_{1}\right)$ & & $\operatorname{Prob}\left(H_{0}\right)$ \\
\hline Risk aversion effect & $\partial \bar{x}_{s} / \partial \sigma>0$ & 0.000 \\
Income effect & $\partial \bar{x}_{s} / \partial w<0$ & 0.000 \\
\hline Note: Calculated from 30,000 MCMC samples from & Model 2
\end{tabular}

Our previous three models included controls for basic individual differences, such as age, gender, education, and growing up in the former GDR. We obtain the same result for the role of risk aversion when excluding all covariates. Moving towards the other extreme, model (4) includes an extended set of covariates, which have been found to influence ideology, including indicator variables of current unemployment, being member of a trade union, or self-employed, being of non-German nationality, hours worked, previous experience of unemployment, and household size. While their inclusion clearly increases endogeneity issues, we argue that even after conditioning on these characteristics individuals are still highly heterogeneous with respect to their level of risk aversion. Accordingly, model (4) shows a remarkably similar estimate for risk aversion, with a slightly increased uncertainty, as evidenced by the wider HPD region.

Before examining the substantive size of the risk aversion effect vis-à-vis income, we perform another strict test of our central hypotheses, formulated in Proposition 1. Table 3 shows Bayesian p-values, which represent directional (one-sided) tests of our income and risk aversion hypotheses. It strongly confirms our results from Table 2: our predictions regarding risk aversion are strongly supported by the current evidence.

Substantive magnitude In order to assess the substantive magnitude of the influence of risk aversion on ideology we compare its effect to that of income. In Figure 2 we calculate marginal effects at each decile of the respective distribution of income and risk aversion (based on estimates of model 2). Our results show the expected marked negative effect of income, which is especially apparent at higher deciles of the income distribution. However, and perhaps surprisingly for a variable far less tangible than income, risk aversion matters just as much. As Figure 2 shows, increasing risk aversion leads to more leftist ideological positions. The magnitude of this effect rivals that of income. 
a

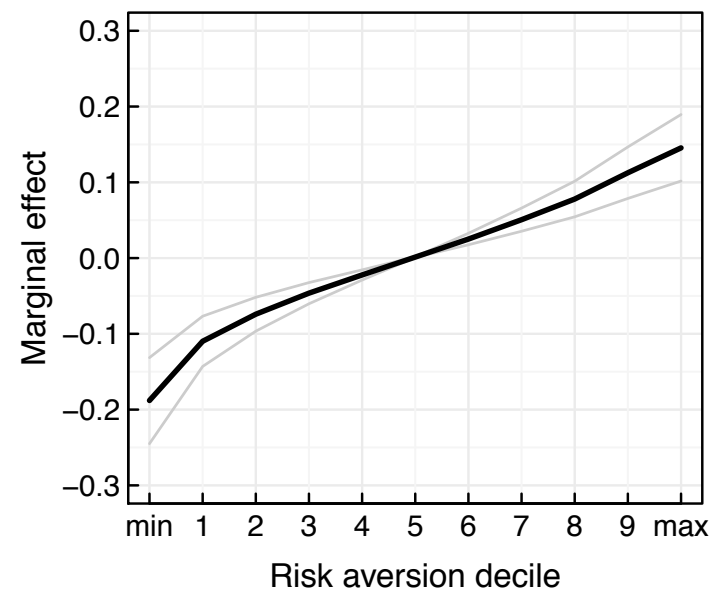

b

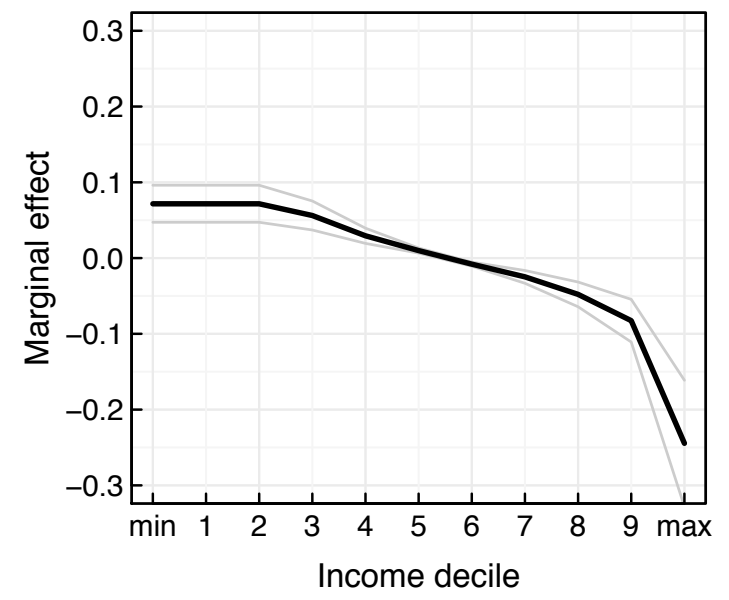

Figure 2: Marginal effects of (a) risk aversion and (b) income distance on ideology. Posterior means and 90\% HPD intervals of marginal effects evaluated at deciles of each variable.

\section{Risk-dependent income effect}

We now turn to examine a further implication of our model: the prediction that the effect of income is dependent on levels of risk-aversion. The vast majority of political-economic models of preference formation treat the effect of income on preferences or ideology as homogeneous over individuals (as did we in the previous section). However, in Part 2 of Proposition 1 we derived the expectation of an income effect heterogeneous in risk aversion. More precisely, we predict that the effect of income on ideology decreases in absolute value monotonously with increasing risk aversion. To study this prediction we replace the income term, $\delta w_{i}$ in our ideology equation in (11) with the interaction specification $\delta\left(w_{i}+w_{i} \psi_{i}\right)$. The second element of vector $\boldsymbol{\delta}$ captures how the effect of income on ideology depends on an individuals' level of risk aversion. In order to interpret results more intuitively, Figure 3 plots marginal income effects at different levels of risk aversion with their associated 90\% HPD regions.

While there is considerable uncertainty around the marginal effect estimates, Figure 3 still illustrates that the income effect is heterogeneous in risk aversion. In line with the prediction from our model, as risk aversion increases, the effect of income on ideology weakens. For individuals with low levels of risk aversion (say one standard deviation below the population mean, $\psi_{i}<-1.6$ ) we find a strong negative marginal effect of income, while for highly averse individuals $\left(\psi_{i}>1.6\right)$ the income effect is reduced considerably. In fact, for individuals with extreme levels of risk aversion $\left(\psi_{i}>2\right)$ the effect of income on ideology is not statistically distinguishable from zero. 


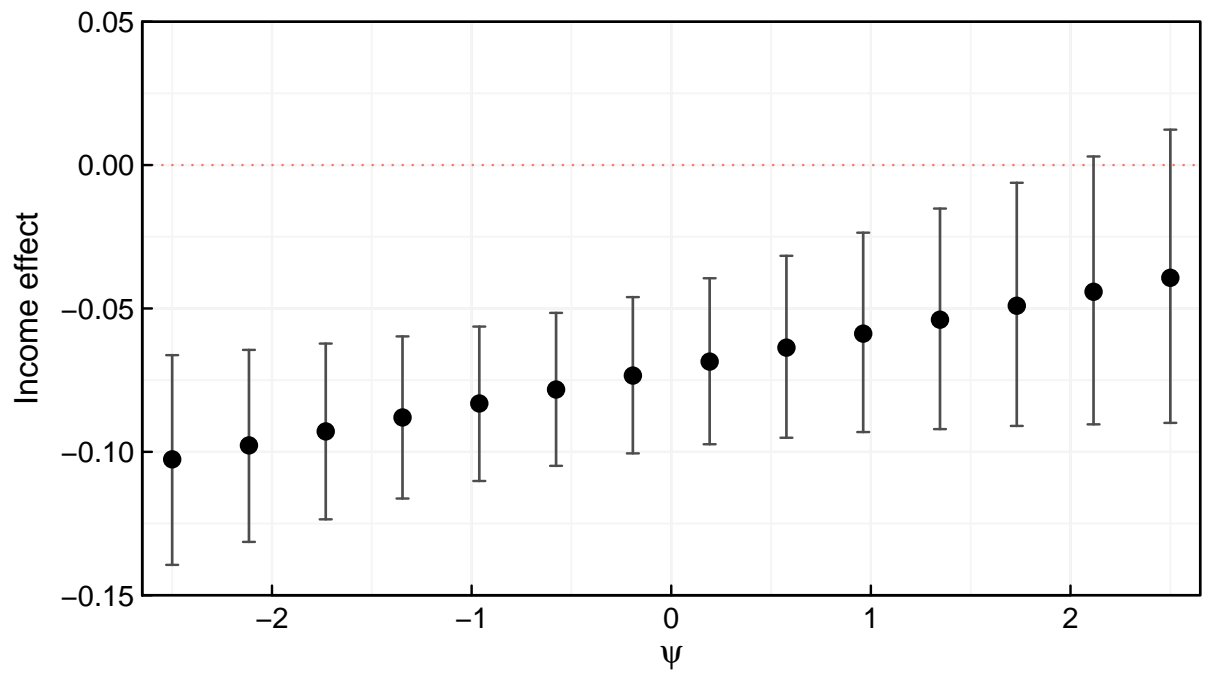

Figure 3: Marginal income effect at different levels of risk aversion

This finding has wider implications for existing political economic models invoking risk aversion. Remember that our results are based on a large-scale population sample, which is arguably better suited to detect high levels of risk aversion (than, say, a lab experiment involving students). Still, we do not find that individuals are so risk averse that an increase in income can increase support for social spending or induce a leftward shift in ideology, as hypothesized by Moene and Wallerstein in their seminal paper (Moene and Wallerstein 2001).

\section{Robustness tests}

To study the robustness of our results we conducted several additional analyses.

Occupational risk So far we have developed our analysis focusing on the central role of risk aversion controlling for a number of covariates. As discussed in the introduction, one factor receiving considerable attention in the recent literature is occupation-specific risk of unemployment (Rehm 2009; Cusack, Iversen, and Rehm 2006), which we have not included in our analysis. In Part 3 of Proposition 1 we show that risk aversion emerges as a distinct factor shaping preferences. In other words, we should find a substantively strong effect of risk aversion even when accounting for occupational unemployment risk. This is borne out empirically. Studying the distribution of risk aversion in occupational groups (not shown here), we do indeed find that at each level of occupational unemployment individuals are still highly heterogeneous in their levels of risk aversion. For a stricter statistical test, we 
include a direct measure of occupational unemployment risk (Rehm 2009; Cusack, Iversen, and Rehm 2006). ${ }^{22}$ Our results show that, while occupational unemployment risk emerges as a significant factor shaping ideology, risk aversion remains highly relevant. Our estimate of risk aversion is $0.050 \pm 0.011$.

Non-economic motivations We have developed our analytical model, explicitly allowing for the fact that an individual's ideology is possibly shaped by many considerations. One of these are spending preferences, whose dependency on risk aversion we have modeled systematically. As long as an increase in spending preferences yields a (left) shift in ideology we can analyze the effect of risk aversion. However, one might argue that an important conflicting element of ideology are values and moral considerations. While we do not have direct measures of these, we include religion as proxy to capture non-economic aspects of an individual's ideological position. ${ }^{23}$ To the extent that religion is related to moral or value-based ideological considerations, we can capture this effect. Our results show that (as expected) religion does have an effect on ideology, but even after its inclusion risk aversion still emerges as highly relevant. Our estimated effect of risk aversion is $0.049 \pm 0.011$.

Wealth In our previous analyses we only included an individual's current income, thus ignoring the role of wealth. Both positive and negative wealth shape an individual's economic security and thus have straightforward effect on (economic) ideology (see, e.g., Ansell 2014). The question is how their inclusion alters our estimate of risk aversion. We include a respondent's net wealth in 2007 (for details on its calculation see appendix A.3) in our ideology equation. We find the effect of risk aversion to still be highly relevant, albeit slightly reduced (estimated as $0.048 \pm 0.01$ ).

\section{CONCLUSION}

In this paper we establish the importance of risk aversion in shaping political ideology. We provide an explicit formal, political economy model that links the two ends of this relationship through an "economic" channel. Our argument is that more risk averse individuals demand more social spending to address risks, such as unemployment in the labor market. A greater demand for social spending in turn shifts individuals' ideological location to the left in the

\footnotetext{
${ }^{22}$ We measure occupational unemployment risk following Rehm (2009) by calculating occupational risk of unemployment from Labor force survey data. For each 2-digit occupation (ISCO) groups, we estimate the proportion of unemployed individuals. Our estimation takes into account survey sample inclusion probabilities.

${ }^{23}$ We measure religion using an individual's denominational self-categorization, i.e., if she considers herself either Catholic, Protestant, member of another faith, or no faith at all.
} 
political spectrum. We provide empirical evidence to support this argument. Our results support the conclusion that risk aversion is strongly related, both substantively and statistically, to individuals' political-ideological position on a left-right scale. This effect is robust to a variety of controls and specifications. The magnitude of the effect of risk aversion is approximately as strong as a person's income on political ideology. We also uncover evidence for another prediction of our model, namely that the effect of income on ideology is not constant over individuals. Rather, we find that the effect of income weakens as individuals become more risk averse.

Some important implications follow from our findings. Our results examine the essential, but hitherto untested, assumption of risk aversion in core models of political economy. Risk aversion is a critical ingredient in social insurance and skill specificity arguments for redistribution in respectively Moene and Wallerstein (2001) and Iversen and Soskice (2001). Our results support the assumption of risk aversion in both models. But we do not find (empirically) the extreme levels of risk aversion necessary to change the sign of an individual's income effect as hypothesized in Moene and Wallerstein (2001).

Finally, our formal model and its empirically tested predictions also contribute to our understanding of popular support for the welfare state. A virtue of our model is that we are now able to distinguish precisely the effects of risk aversion from those of unemployment risk. This later variable is the focus of much recent research. We do not wish to challenge the empirical importance of unemployment risk this research uncovers (e.g., Cusack, Iversen, and Rehm 2006; Rehm 2009, 2011b; Rehm, Hacker, and Schlesinger 2012). But our model illustrates that risk neutral individuals will have no desire for social insurance, but may prefer more social spending for purely redistributive reasons if they are subject to greater risk of unemployment. Thus, we argue that individuals' risk aversion better captures (and makes theoretically explicit) the behavioral elements underlying the insurance view of the welfare state.

\section{REFERENCES}

Achen, C. 2005. "Let's Put Garbage-Can Regressions and Garbage-Can Probits Where They Belong." Conflict Management and Peace Science 22 (4): 327-339.

Alesina, A., and N. Fuchs-Schündeln. 2007. "Good-Bye Lenin (or Not?): The Effect of Communism on People's Preferences." American Economic Review 97 (4): 1507-1528.

Anderson, J. A. 1984. "Regression and Ordered Categorical Variables." Journal of the Royal Statistical Society B 46 (1): 1-30. 
Anderson, T. W., and H. Rubin. 1956. "Statistical inference in factor analysis." In Proceedings of the third Berkeley symposium on mathematical statistics and probability, ed. J. Neyman. Vol. 5, Berkeley pp. 111-150.

Ansell, B. 2014. "The Political Economy of Ownership: Housing Markets and the Welfare State." American Political Science Review 108 (2): 383-402.

Bartholomew, D. 1988. "The sensitivity of latent trait analysis to choice of prior distribution." British Journal of Mathematical and Statistical Psychology 41 (1): 101-107.

Camerer, C. F., and R. M. Hogarth. 1999. "The effects of financial incentives in experiments: A review and capital-labor-production framework." Journal of Risk and Uncertainty 19 (1-3): $7-42$.

Chesher, A. 1991. "The effect of measurement error." Biometrika 78 (3): 451-462.

Cusack, T., T. Iversen, and P. Rehm. 2006. "Risks At Work: The Demand And Supply Sides Of Government Redistribution." Oxford Review Of Economic Policy 22 (3): 365-389.

Dohmen, T. J., A. Falk, D. Huffman, U. Sunde, J. Schupp, and G. G. Wagner. 2005. "Individual risk attitudes: New evidence from a large, representative, experimentally-validated survey." IZA Discussion paper.

Douglas, M., and A. Wildavsky. 1983. Risk and culture: An essay on the selection of technological and environmental dangers. Univ of California Press.

Ferguson, T. S. 1983. "Bayesian density estimation by mixtures of normal distributions." In Recent Advances in Statistics, ed. M. Rizvi, J. Rustagi, and D. Siegmund. Number 1983 New York: Academic Press.

Frick, J. R., M. M. Grabka, and J. Marcus. 2007. "Editing and Multiple Imputation of ItemNon-Response in the 2002 Wealth Module of the German Socio-Economic Panel (SOEP)." SOEP Survey Papers, No. 148.

Fuller, W. A. 1987. Measurement error models. New York: John Wiley \& Sons.

Gerber, A. S., G. a. Huber, D. Doherty, C. M. Dowling, and S. E. Ha. 2010. "Personality and Political Attitudes: Relationships across Issue Domains and Political Contexts." American Political Science Review 104 (01): 111.

Gill, J. 2014. Bayesian Methods. A Social and Behavioral Sciences Approach. 3rd Edition. Boca Raton: Chapman \& Hall.

Haisken-DeNew, J. P., and J. R. Frick. 2005. Desktop Companion to the German Socio-Economic Panel (SOEP). Technical report.

Hinich, M. J., and M. C. Munger. 1992. "A spatial theory of ideology." Journal of Theoretical Politics 4 (1): 5-30. 
Hinich, M. J., and M. C. Munger. 1996. Ideology and the theory of political choice. University of Michigan Press.

Holt, C. A., and S. K. Laury. 2002. "Risk aversion and incentive effects." American Economic Review 92 (5): 1644-1655.

Iversen, T., and D. Soskice. 2001. "An Asset Theory of Social Policy Preferences." American Political Science Review 95 (4): 875-893.

Jackman, S. 2008. "Measurement." In Oxford Handbook of Political Methodology, ed. J. M. Box-steffensmeier, H. E. Brady, and D. Collier. Oxford: Oxford University Press.

Jackman, S. D. 2009. Bayesian Analysis for the Social Sciences. New York: Wiley.

Kam, C. D. 2012. "Risk attitudes and political participation." American Journal of Political Science 56 (4): 817-836.

Moene, K. O., and M. Wallerstein. 2001. "Inequality, Social Insurance and Redistribution." American Political Science Review 95 (4): 859-874.

Mondak, J. J., and K. D. Halperin. 2008. "A framework for the study of personality and political behaviour." British Journal of Political Science 38 (02): 335-362.

Mondak, J. J., M. V. Hibbing, D. Canache, M. A. Seligson, and M. R. Anderson. 2010. "Personality and civic engagement: An integrative framework for the study of trait effects on political behavior." American Political Science Review 104 (01): 85-110.

Morton, R., J.-R. Tyran, and E. Wengstrom. 2011. "Income and Ideology: How Personality Traits, Cognitive Abilities, and Education Shape Political Attitudes." Discussion Papers. Department of Economics, University of Copenhagen.

Quinn, K. M. 2004. "Bayesian Factor Analysis for Mixed Ordinal and Continuous Responses." Political Analysis 12: 338-353.

Rehm, P. 2009. "Risks and Redistribution: An Individual-Level Analysis." Comparative Political Studies 42 (7): 855-881.

Rehm, P. 2011a. "Risk Inequality and the Polarized American Electorate." British Journal of Political Science 41 (2): 363-387.

Rehm, P. 2011b. "Social policy by popular demand." World Politics 63 (02): 271-299.

Rehm, P., J. S. Hacker, and M. Schlesinger. 2012. "Insecure alliances: Risk, inequality, and support for the welfare state.” American Political Science Review 106 (02): 386-406.

Rossi, P. 2014. Bayesian Non-and Semi-parametric Methods and Applications. Princeton: Princeton University Press. 
Rothschild, M., and J. E. Stiglitz. 1970. "Increasing risk: I. A definition.” Journal of Economic theory 2 (3): 225-243.

Socio-Economic Panel (SOEP). 2013. Data for Years 1984-2012, version 29. doi: 10.5684/soep.v29.

Skrondal, A., and S. Rabe-Hesketh. 2004. Generalized latent variable modeling: Multilevel, longitudinal and structural equation models. Boca Raton: Chapman \& Hall.

Vecchione, M., and G. V. Caprara. 2009. "Personality determinants of political participation: The contribution of traits and self-efficacy beliefs." Personality and Individual Differences 46 (4): 487-492.

Wagner, G. G., J. R. Frick, and J. Schupp. 2007. "The German Socio-Economic Panel Study (SOEP)-Scope, Evolution and Enhancements." Schmollers Jahrbuch 127 (1): 139-169.

Wansbeek, T., and E. Meijer. 2000. Measurement Error and Latent Variables in Econometrics. Amsterdam: North Holland.

Weber, E. U., A.-R. Blais, and N. E. Betz. 2002. "A domain-specific risk-attitude scale: Measuring risk perceptions and risk behaviors." Journal of Behavioral Decision Making 15: 263-290.

Wedel, M., and W. A. Kamakura. 2001. "Factor analysis with (mixed) observed and latent variables in the exponential family." Psychometrika 66 (4): 515-530.

Wildavsky, A. 1987. "Choosing preferences by constructing institutions: A cultural theory of preference formation." American Political Science Review 81 (01): 3-21. 


\section{A. AppendiX}

\section{A.1. Equilibrium Uniqueness and Existence}

Proposition 2. An equilibrium is a triple, $\left\{l_{s}^{*}, \tau_{s}^{*}, \bar{x}_{i, s}\right\}$. For each $s$, an equilibrium exists and is unique.

We begin at the final stage of the model. Only employed workers supply labor, so each employed worker chooses $l$ to maximize utility $u\left(c_{E}\right)$ subject to her consumption (5), and taking taxes and transfers as given. Taking the derivative of this equation and setting it equal to zero, leads to the unique equilibrium value of labor supply for each type:

$$
l_{w}^{*}=C_{l}^{-1}[(1-\tau) w]
$$

Existence and uniqueness is ensured by the convexity of $C(\cdot)$. Convexity of $C(\cdot)$ also implies that $l_{w}^{*}$ is increasing in $l$, decreasing in $\tau$. Also note that $l_{w}^{*}$ does not depend on $\sigma$. Hence, we subscript with $w$ rather than $s$. For the same reason we will write income as $y_{w}=w l_{w}^{*}$. Finally we will assume that $C_{l}^{-1}(\cdot)$ is a weakly concave function, which will ensure that the second-order conditions are straightforwardly met.

We turn now to workers' social spending preferences. The program is:

$$
\max _{\tau} q_{s} u\left(c_{E}\right)+\left(1-q_{s}\right) u\left(c_{N}\right)
$$

subject to the consumption constraints (5) and (6) and the government budget constraint (4). Applying the envelope theorem, this gives the first-order condition for $\tau$ as

$$
q_{s} u^{\prime}\left(c_{E}\right)\left[\left(\frac{\chi}{\bar{q}}\right)\left(\bar{z}+\tau \bar{z}_{\tau}\right)-y_{w}\right]+\left(1-q_{s}\right) u^{\prime}\left(c_{N}\right)\left(\frac{1-\chi}{1-\bar{q}}\right)\left(\bar{z}+\tau \bar{z}_{\tau}\right)=0 .
$$

Two implications should be clear from this first-order condition. First, $\bar{z}>0$ represents the marginal benefit of the transfer and $\tau \bar{z}_{\tau}<0$ represents the marginal cost. Second, since $-y_{w}<0$, satisfing the first-order condition requires $\left(\bar{z}+\tau \bar{z}_{\tau}\right)-y_{w} \leq 0$ and $\left(\bar{z}+\tau \bar{z}_{\tau}\right) \geq 0$. These implications will be important for the proofs that follow.

To give the first-order condition some intuition, let $\xi(\bar{z}, \tau) \equiv \bar{z}_{\tau}(\tau / \bar{z})<0$ be the elasticity of public funds with respect to the tax rate. Then, when social spending is targeted to the unemployed $\left(\chi=0\right.$ ), after rearranging (14) the optimal level of social spending $\tau_{s}^{*}$ is given by:

$$
1-\left(\frac{q_{s}}{1-q_{s}}\right)\left(\frac{u^{\prime}\left(c_{E}\right)}{u^{\prime}\left(c_{N}\right)}\right) \frac{y_{w}}{\bar{z}}+(1-\bar{q}) \xi(\bar{z}, \tau)=0
$$


When transfers are universal $(\chi=\bar{q})$, the first-order condition can be rearranged to give:

$$
1-\left(\frac{q_{s}}{1-q_{s}}\right)\left(\frac{u^{\prime}\left(c_{E}\right)}{u^{\prime}\left(c_{N}\right)}\right)\left[\frac{y_{w}}{\bar{z}}-(1+\xi(\bar{z}, \tau))\right]+\xi(\bar{z}, \tau)=0
$$

Finally, when transfers are targeted to employed workers $(\chi=1)$, the first-order condition is:

$$
1-\frac{y_{w}}{\bar{z}}+\xi(\bar{z}, \tau)=0
$$

These formulations of the first-order condition are convenient, since they capture the three critical effects of Proposition 1 . The term $q_{s} /\left(1-q_{s}\right)$ captures the effect of unemployment risk. The $u^{\prime}\left(c_{E}\right) / u^{\prime}\left(c_{N}\right)$ term is the marginal rate of substitution between employed and unemployed consumption, and captures the effect of risk aversion. The $y_{w} / \bar{z}$ term is the ratio between individual income and average government revenues, which captures the (pure) income effect.

It is easily checked that the second-order condition is satisfied. From the concavity of $C_{l}^{-1}(\cdot)$, differentiating equation (14) once again with respect to $\tau$ yields a strictly negative expression. This condition ensures the existence and uniqueness of an individually-optimal choice of social spending, $\tau_{s}^{*}$.

Finally, we derive the effect of social spending preferences on an individual's ideological location. Let policy $i$ represent social spending, then $\bar{x}_{i, s}\left(\tau_{s}^{*}\right)=\tau_{s}^{*}$. We then can say that anything that increases (decreases) an individual $s$ 's social spending preferences moves her ideologically to the left (right): $\partial \bar{x}_{i, s} / \partial \tau_{s}^{*}=1>0$.

\section{A.2. Proof of Proposition 1}

Since the second-order conditions are satisfied, by the implicit function theorem the sign of $\partial \tau_{s}^{*} / \partial m$ for any parameter $m$ is the sign of $d m$. Further, by applying the Chain Rule, it then follows that a change in any parameter has an effect with identical sign, that is, $\operatorname{sign}\left(\partial \bar{x}_{i, s} / \partial \tau_{s}^{*} \cdot \partial \tau_{s}^{*} / \partial m\right)=\operatorname{sign}\left(\partial \tau_{s}^{*} / \partial m\right)$. 
Beginning with the effects of risk aversion, differentiate equation (14) with respect to $\sigma$ to get:

$$
\begin{aligned}
-q_{s} u^{\prime}\left(c_{E}\right) \ln \left(c_{E}\right)\left[\left(\frac{\chi}{\bar{q}}\right)\left(\bar{z}+\tau \bar{z}_{\tau}\right)-y_{w}\right] & \\
& -\left(1-q_{s}\right) u^{\prime}\left(c_{N}\right) \ln \left(c_{N}\right)\left(\frac{1-\chi}{1-\bar{q}}\right)\left(\bar{z}+\tau \bar{z}_{\tau}\right)
\end{aligned}
$$

This equation is identical to (14) except the $\ln (\cdot)$ terms and the possible changes in sign. Therefore, since $c_{E} \geq c_{N}$ is always true and implies $\ln \left(c_{E}\right) \geq \ln \left(c_{N}\right)$, the entire expression is always positive. ${ }^{24}$ Note that in the case $\chi=1$, equation (18) becomes

$$
-q_{s} u^{\prime}\left(c_{E}\right) \ln \left(c_{E}\right)\left[\left(\frac{1}{\bar{q}}\right)\left(\bar{z}+\tau \bar{z}_{\tau}\right)-y_{w}\right]
$$

which from the first-order condition in that case, $(1 / \bar{q})\left(\bar{z}+\tau \bar{z}_{\tau}\right)-y_{w}=0$, must be zero. Intuitively, risk aversion plays no role in social-policy preferences when transfers have no insurance element to them. Thus, except in this limiting case, an increase in risk aversion always increases social spending preferences: $\partial \tau_{s}^{*} / \partial \sigma>0$.

Turning to income, differentiate equation (14) with respect to $y_{w}$ and write:

$$
u^{\prime}\left(c_{E}\right)(\sigma \mu-1)
$$

using the fact that $\sigma=-c u^{\prime \prime}(c) / u^{\prime}(c)$ and where,

$$
\mu=\frac{\left[y_{w}-(\chi / \bar{q})\left(\bar{z}+\tau \bar{z}_{\tau}\right)\right](1-\tau)}{\left[(1-\tau) y_{w}+(\chi / \bar{q}) \tau \bar{z}-C(l)\right]} .
$$

Moene and Wallerstein (2001) call $\mu$ the elasticity of consumption when working with respect to $1-\tau$. Start with the case $\chi=0$, which makes $\mu$ in equation (20), denoted $\mu^{\prime}=(1-\tau) y_{w} /\left[(1-\tau) y_{w}-C(l)\right]>1$. Let $\sigma^{\prime}$ be the value of $\sigma$ that gives $\sigma^{\prime} \mu^{\prime}-1=0$. Then equation (19) is nonnegative for all $\sigma \geq \sigma^{\prime}$ and negative for all $\sigma<\sigma^{\prime}$. Thus, in the case $\chi=0, \partial \tau_{s}^{*} / \partial y_{w} \geq 0$ for all $\sigma \geq \sigma^{\prime}$ and $\partial \tau_{s}^{*} / \partial y_{w}<0$ for all $\sigma<\sigma^{\prime}$.

An analogous argument holds for the case $\chi=\bar{q}$. Let $\mu^{\prime \prime}$ be the value of (20) when $\chi=\bar{q}$. For any value of $\tau$, we have $y_{w}-\left(\bar{z}+\tau \bar{z}_{\tau}\right)<y_{w}$ and $(1-\tau) y_{w}+\tau \bar{z}-C(l)>(1-\tau) y_{w}-C(l)$.

\footnotetext{
${ }^{24}$ Note in particular that the term on the left of (18) is positive for all $c_{E} \geq 1$ and larger in absolute value than the term on the right, which is nonpositive for all $c_{N} \geq 1$. For all $c_{E} \geq 1$ and all $0 \leq c_{N}<1$, the whole expression is positive. Finally, for all $0 \leq c_{E}<1$ and all $0 \leq c_{N}<1$ the term on the left is negative and smaller in absolute value than the term on the right, which is positive, which again makes the entire expression positive.
} 
Therefore, it is clear that $\left[y_{w}-\left(\bar{z}+\tau \bar{z}_{\tau}\right)\right](1-\tau) /\left[(1-\tau) y_{w}+\tau \bar{z}-C(l)\right]=\mu^{\prime \prime}<\mu^{\prime}$. This implies that $\sigma^{\prime \prime}>\sigma^{\prime}$, where $\sigma^{\prime \prime}$ is the value of $\sigma$ for which (19) equals zero when $\chi=\bar{q}$. Thus, in the case $\chi=\bar{q}, \partial \tau_{s}^{*} / \partial y_{w} \geq 0$ for all $\sigma \geq \sigma^{\prime \prime}$ and $\partial \tau_{s}^{*} / \partial y_{w}<0$ for all $\sigma<\sigma^{\prime \prime}$.

Finally, for $\chi=1$, this value of $\chi$ implies from the first-order condition that $(1 / \bar{q})\left(\bar{z}+\tau \bar{z}_{\tau}\right)-$ $y_{w}=0$. Hence, (19) is negative for $\chi=1$ and $\partial \tau_{s}^{*} / \partial y_{w}<0$ for all $\sigma$.

Finally, we examine the effects of employment and unemployment. Differentiating equation (14) with respect to $q_{s}$ we obtain:

$$
u^{\prime}\left(c_{E}\right)\left[\left(\frac{\chi}{\bar{q}}\right)\left(\bar{z}+\tau \bar{z}_{\tau}\right)-y_{w}\right]-u^{\prime}\left(c_{N}\right)\left(\frac{1-\chi}{1-\bar{q}}\right)\left(\bar{z}+\tau \bar{z}_{\tau}\right) \leq 0
$$

which is negative by the first-order condition. Note that for $\chi=1$, this expression is equal to zero, so some universality is again essential for unemployment risk to influence social spending preferences. Thus, $s$ 's ideal tax rate is decreasing in her employment rate, and therefore increasing in her unemployment rate: $\partial \tau_{s}^{*} / \partial\left(1-q_{s}\right) \geq 0$ for all $\chi<1$. 


\section{A.3. Data details}

Descriptive statistics Table A.1 shows descriptive statistics of all variables.

Table A.1: Descriptive statistics of estimation sample

\begin{tabular}{lrr}
\hline & Mean & SD \\
\hline Risks while driving & 6.78 & 2.57 \\
Financial risks & 8.02 & 2.14 \\
Risks in leisure, sports & 6.60 & 2.57 \\
Risks in occupation & 6.54 & 2.65 \\
General risk taking & 6.12 & 2.16 \\
Ideology (right-left) & 5.33 & 1.63 \\
Age & 44.45 & 11.86 \\
Education & 12.38 & 2.60 \\
Income distance (in 1000 Euro) & 0.00 & 2.00 \\
Household size & 2.80 & 1.24 \\
Unemployment experience & 1.17 & 2.51 \\
Hours worked & 27.84 & 20.36 \\
Female & \multicolumn{2}{c}{$52 \%$} \\
East & $27 \%$ \\
Unemployed & \multicolumn{2}{c}{$8 \%$} \\
Self-employed & \multicolumn{2}{c}{$7 \%$} \\
Foreigner & \multicolumn{2}{c}{$6 \%$} \\
Union member & \multicolumn{2}{c}{$14 \%$} \\
\hline
\end{tabular}

Calculation of wealth Obtaining information on wealth on the individual level is notoriously difficult. In 2007 SOEP includes a comprehensive wealth module with a detailed set of wealth-related items similar to the British Household Panel Study. An individual's net wealth is captured by several components displayed in Table A.2.

Missing responses are particularly problematic when trying to assess an individual's wealth (especially if nonresponse is systematically related to certain wealth components). SOEP provides imputation (accounting for selection effects) of all wealth components using detailed respondent information. For an extensive documentation see Frick, Grabka, and Marcus (2007). Here we use a simple aggregate of all imputed values.

Figure A.1 plots the kernel density estimate of wealth in our sample. 
Table A.2: Wealth components
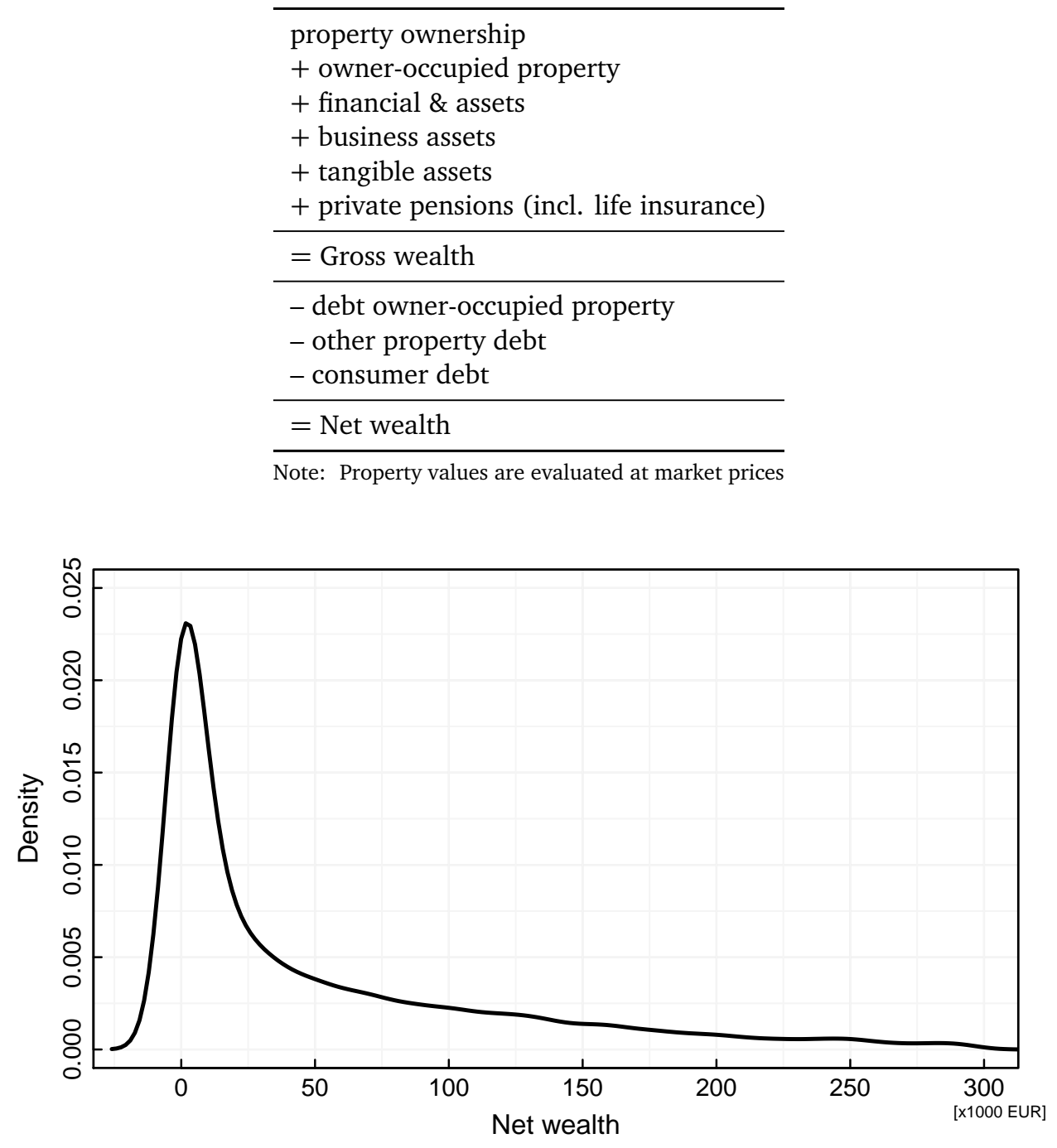

Figure A.1: Density of wealth in sample

\section{A.4. Prior parameter distributions and values}

Table A. 3 shows prior distributions and prior values for our model in the main text. Columns 'Prior test' 1 and 2 display alternative parametrizations to check for the robustness of our analysis against changes in prior values. Test 1 specifies a priori variances 10 times larger than in our main model. Test 2 uses a different parametrization of the inverse gamma prior for all variances in the model. Under both prior checks we obtain virtually indistinguishable 
parameter estimates for our central model parameters. For example, after rounding to two significant digits, under both test 1 and 2 we estimate $\gamma$ as 0.05 with a posterior SD of 0.01 . 


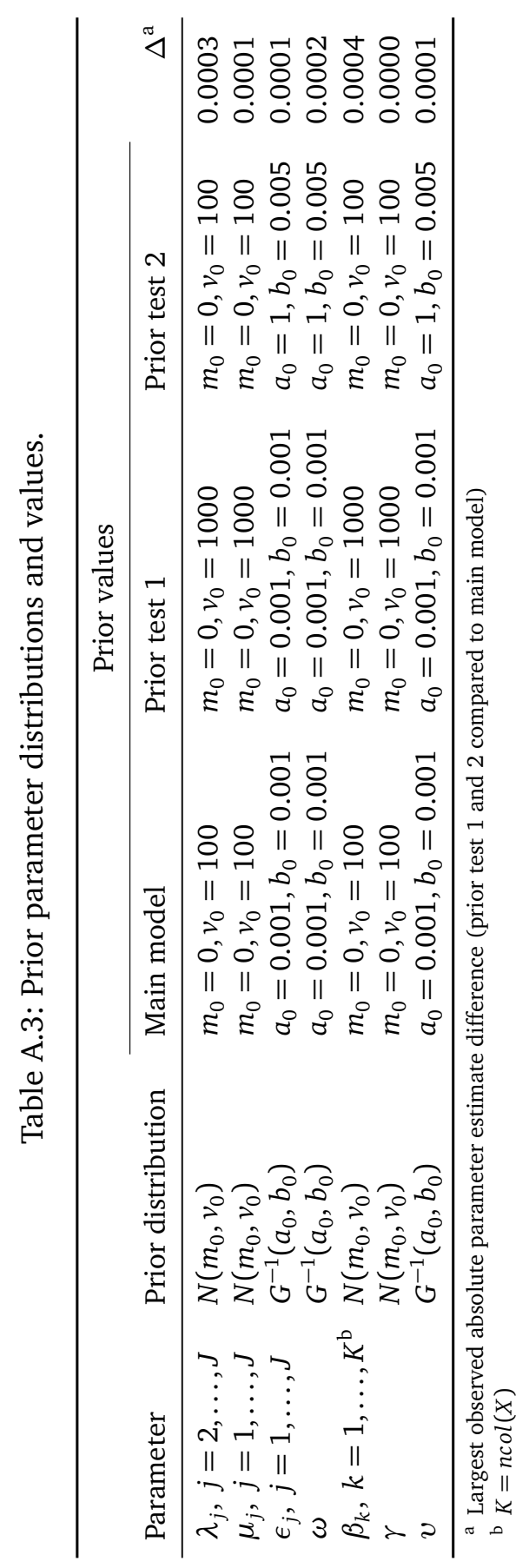

